\title{
"Seminários Livres: Qlínica, com quê?": contribuições de Marcus Vinícius de Oliveira Silva à psicologia brasileira
}

\section{“Free seminars: Qlínica, com quê?": Contributions of Marcus Vinícius de Oliveira Silva to brazilian psychology}

\author{
"Seminarios libres: Qlínica, com quê?": Contribuciones de \\ Marcus Vinicius de Oliveira Silva a la psicología brasileña
}

\author{
Bruna Borba de Araújo Tchalekian* \\ Universidade de São Paulo - USP, São Paulo, São Paulo, Brasil
}

\section{Yasmin de Sousa Pereira**}

Universidade Federal do ABC - UFABC, Santo André, São Paulo, Brasil

\begin{abstract}
RESUMO
O presente artigo tem como objetivo apresentar um estudo inicial sobre o projeto "Seminários Livres: Qlínica, com quê?", construído pelo psicólogo e professor Marcus Vinícius de Oliveira Silva e promovido pelo Laboratório de Estudos Vinculares e Saúde Mental - IPS/UFBA. Os seminários constituíramse como espaços de formação para alunos e profissionais, visando o fortalecimento do trabalho clínico desenvolvido no âmbito da Rede Psicossocial de Saúde Mental. Serão apresentadas discussões referentes ao trabalho da clínica ampliada e ao desenvolvimento de diagnósticos diferenciais no contexto da saúde pública. Conclui-se que o projeto constituiu-se como espaço potente para fortalecimento e reflexão acerca dos desafios do trabalho da rede e sua difusão configura-se como possibilidade de ampliação dos saberes ali desenvolvidos.
\end{abstract}

Palavras-chave: Clínica ampliada, Marcus Vinicius de Oliveira Silva, Qlínica, com quê?

\begin{abstract}
The present article aims to present an initial study on the project "Seminários Livres: Qlínica, com quê?", Built by the psychologist and professor Marcus Vinícius de Oliveira Silva and promoted by the Laboratory of Vincular Studies and Mental Health - IPS / UFBA. The seminars were created as training spaces for students and professionals, aimed at strengthening the clinical work developed within the Psychosocial Network of Mental Health. Discussions will be presented regarding the work of the expanded clinic and the development of differential diagnoses in the context of public health. It is concluded that the project constituted as a powerful space for strengthening and reflection on the challenges of the work of the network and its diffusion is configured as a possibility to expand the knowledge developed there.
\end{abstract}


Keywords: Extended general practice, Marcus Vinicius de Oliveira Silva, Qlínica, com quê?

\section{RESUMEN}

El presente artículo tiene como objetivo presentar un estudio inicial sobre el proyecto "Seminarios Livres: Qlínica, con qué?", construido por el psicólogo y profesor Marcus Vinícius de Oliveira Silva y promovido por el Laboratorio de Estudios Vinculares y Salud Mental - IPS/UFBA. Los seminarios se constituyeron como espacios de formación para alumnos y profesionales, buscando el fortalecimiento del trabajo clínico desarrollado en el ámbito de la Red Psicosocial de Salud Mental. Se presentarán discusiones sobre el trabajo de la clínica ampliada y el desarrollo de diagnósticos diferenciales en el contexto de la salud pública. Se concluye que el proyecto se constituyó como espacio potente para el fortalecimiento y reflexión acerca de los desafíos del trabajo de la red y su difusión se configura como posibilidad de ampliación de los saberes allí desarrollados.

Palabras clave: Clínica ampliada, Marcus Vinicius de Oliveira Silva, Qlínica, com quê?

\section{"Seminários Livres: Qlínica, com quê?": contribuições de Marcus Vinícius de Oliveira Silva à psicologia brasileira}

O tema das equipes, da interdisciplinaridade, multidisciplinaridade, eu costumo brincar que eu comecei sendo disciplinar, depois eu fui multidisciplinar, depois eu fui interdisciplinar, depois eu fui transdisciplinar e atualmente eu sou indisciplinado. (Silva, 2014a, 43:00)

Marcus Vinícius de Oliveira Silva foi um dos pioneiros na luta pela reforma psiquiátrica no Brasil e na criação de Centros de Atenção Psicossocial, os CAPS. Professor pela Universidade Federal da Bahia (UFBA), sua trajetória foi marcada por significativa contribuição e militância nos campos da Saúde Mental, Saúde Coletiva e Direitos Humanos, no fortalecimento da Psicologia como ciência e profissão, com atuação junto aos Conselhos Federal e Regional de Psicologia. Após seu falecimento em fevereiro de 2016, o Instituto Silvia Lane de Psicologia e Compromisso Social iniciou o desenvolvimento do projeto Memorial Matraga, plataforma online que reúne as contribuições do autor nos diversos campos com os quais dialogou. A proposta do memorial volta-se à difusão do conhecimento produzido por Marcus Vinícius, reconhecendo sua relevância para a Psicologia brasileira e latino-americana. As autoras do presente artigo trabalharam junto ao tratamento e compilação do acervo do autor.

Com o intuito de prosseguir na ampla difusão dos estudos e produções de Marcus Vinícius, o objetivo deste artigo é apresentar as contribuições de temas abordados nos "Seminários Livres: Qlínica com quê?", programa proposto e coordenado pelo referido professor e psicólogo. Projeto promovido pelo Laboratório de Estudos 
Vinculares e Saúde Mental - IPS/UFBA, com apoio e espaço cedido pelo Centro de Estudos e Terapia do Abuso de Drogas- CETAD, tinha como proposta o diálogo com profissionais atuantes no campo da saúde mental acerca do trabalho clínico desenvolvido no âmbito da Rede Psicossocial. Os encontros, registrados através de vídeos e conduzidos por Marcus Vinícius, abordaram diversos temas relacionados à atuação profissional junto a clínica ampliada, bem como os desafios percebidos nessa interface. Entende-se que os seminários constituíram-se como espaços de formação e fortalecimento de rede, compondo, assim, a história social da psicologia brasileira. Tal conteúdo mostra-se relevante não só como forma de resgatar o processo de constituição da Reforma Psiquiátrica e seus atravessamentos, mas também as discussões desenvolvidas no âmbito do projeto que são significativamente atuais no que tange à constituição de equipes e sua formação profissional e os elementos políticos que envolvem o desenvolvimento dos serviços em saúde mental, bem como a importância de reafirmar compromissos com o desenvolvimento de estratégias de cuidado e garantia de direitos fundamentais frente ao atual cenário de desmonte e retrocesso de políticas públicas neste campo.

Dessa forma, a proposta deste artigo é apresentar as contribuições dos "Seminários Livres: Qlínica com quê?", realizando um mapeamento inicial de seu conteúdo, a fim de ampliar o conhecimento ali produzido. Considera-se que a análise acerca da proposta dos seminários não se esgota aqui, pelo contrário; apresentamos uma discussão inicial, apontando para a importância do aprofundamento sobre cada tema em futuros estudos. Por se tratar de discussões registradas em vídeo, as referências apresentadas dizem respeito ao conteúdo audiovisual do projeto. Inicialmente, falaremos sobre os temas tangenciados no encontro dos Seminários Livres ocorridos em 04 de novembro de 2014, sobre o tema "A clínica ampliada da coisa mental: desinstitucionalização e substitutividade" e nos dias 17 e 24 de março de 2015, cujo tema central é "Diagnóstico diferencial: patologias ou formas de existência humana?". Assim, as principais fontes de dados aqui utilizadas foram os vídeos que registram os encontros, apresentados em interlocução com reflexões feitas acerca dos temas centrais e da proposta do autor. Não pretende-se propor um aprofundamento teórico em campos específicos, como a Psicanálise, citada por Silva em alguns momentos da discussão; contudo, entende-se que é necessário apontá-los como forma de apresentar os campos de interlocução do autor em sua trajetória acadêmica e política. 


\section{A Clínica ampliada da coisa mental: Desinstitucionalização e substitutividade}

A proposta apresentada por Silva (2014a) à discussão, inicia-se com a definição do termo ampliada no contexto clínico em questão. Para o autor, a noção de clínica ampliada é apresentada como uma denúncia à existência de uma outra clínica em formato restrito. O modelo de clínica em saúde mental restrita foi presente até o advento da Reforma Psiquiátrica, momento em que o formato de trabalho foi questionado e alterado, levando em conta as noções de desinstitucionalização e da substitutividade. Segundo Campos (2007) "A clínica ampliada baseia-se na construção de responsabilidade singular e de vínculo estável entre equipe de saúde e paciente." Ou seja, a clínica ampliada diz respeito à perspectiva da desinstitucionalização, no qual refere-se a necessidade de revisão do modelo manicomial, até então instituído (Silva, 2014a):

Então uma clínica desinstitucionalizante se faz a partir de uma crítica histórica ao que foi a institucionalização manicomial. Ela tem o compromisso de ser uma clínica desinstitucionalizante, que faça a superação daquilo que a clínica institucionalizada, a clínica do cuidar com pessoas com transtorno mental feita nos manicômios tinha produzido até então. (Silva, 2014a, 03:09)

Nota-se que Silva indica que a superação, de um modelo institucionalizado para um modelo desinstitucionalizado, não é adotado de forma repentina, mas no bojo de um processo crítico que leva em conta a historicidade do processo de institucionalização em saúde mental, e as possíveis implicações disso.

Segundo o autor, era necessário não apenas desinstitucionalizar, mas desenvolver um projeto substitutivo aos antigos moldes de cuidado em saúde mental, que viesse a "substituir as ideias, os pensamentos, substituir os valores, as práticas (Silva, 2014a, 04:09). Dessa forma, a reforma psiquiátrica pauta-se na proposta antimanicomial, que modificará de forma significativa o fazer clínico. Contudo, a noção a que se refere como antimanicomial amplia-se, para o autor; não mantem-se na dualidade 'com manicômio ou sem manicômio', mas desenvolve-se como proposta integral:

Nesse segmento, o antimanicomial é cultura, antimanicomial é arte, antimanicomial é ética, antimanicomial é um modo de compreender a vida, antimanicomial é política, antimanicomial é muito amplo, tem sua expressão no campo jurídico, no campo legal, o antimanicomial é muito diversificado nas consequências. Eu gosto de frisar sempre que o antimanicomial, ele produz um efeito na cultura, todos os 
âmbitos são tocados por essa ideia do antimanicomial. São tocados, são sensibilizados por essa ideia do antimanicomial. (Silva, 2014a, 05: 16)

Podemos considerar que a noção de antimanicomial produz efeitos na cultura na medida em que adota outra concepção de sujeito, diferente do que antes era tido. Altera perspectivas no âmbito das relações pessoais e coletivas, nas relações de trabalho, na proposta de diálogo e abertura ao outro. Altera noções de saúde e doença. Desta forma, a clínica ampliada propõe uma revisão no modelo de tratamento até então estabelecido, alterando, assim, o fazer dentro dessa prática. Rever, nesse sentido, não se refere a negar o conhecimento anteriormente produzido, mas a tecer críticas do ponto de vista da autoridade que determinadas áreas tinham sobre o campo, em vistas do que poderia ser alterado, repensado, transformado (Silva, 2014a).

Silva segue com a discussão exemplificando como o diálogo com outras áreas, tal como as contribuições das noções fenomenológicas de psicopatologia aos modos de sentir do sujeito, passam a ter espaço nessa nova conjuntura. As contribuições da psicanálise também são significativas nesse processo, na medida em que trabalha com noções importantes ao fazer clínico, como é o caso do conceito de transferência, que contribui para o olhar sobre o vínculo, fundamental na perspectiva da clínica ampliada. De acordo com Roudinesco e Plon (1997), a transferência é um:

Termo progressivamente introduzido por Sigmund Freud e Sandor Ferenczi (entre 1900 e 1909), para designar um processo constitutivo do tratamento psicanalítico mediante o qual os desejos inconscientes do analisando concernentes a objetos externos passam a se repetir, no âmbito da relação analítica, na pessoa do analista, colocado na posição desses diversos objetos (Roudinesco e Plon, 1997, p. 766-767)

Vale ressaltar Nunes (2004), ao salientar que a transferência não é um termo específico da psicanálise, mas um vocábulo utilizado em diversos campos, denotando sempre uma ideia de transporte, de deslocamento, de substituição de um lugar para outro, portanto essencial ao se pensar o fazer da clínica ampliada que revê o modelo até então instituído. Silva (2014), afirma:

Não se trata de abolir a importância do conhecimento sistematizado, do conhecimento teórico, do conhecimento técnico sistematizado, mas se trata de questionar, arguir, suspeitar da sua autoridade, em nome de uma reinterpretação crítica desses conhecimentos para ver o que passa no crivo de 
desinstitucionalização e da substitutividade. (Silva, 2014a, 11:14)

Nessa premissa, há o questionamento sobre a segregação das áreas da saúde, como psicologia, psiquiatria, enfermagem, terapia ocupacional, que relacionavam-se de forma corporativista (Silva, 2014a), e passam também a ser revistas, para o que virá a ser a proposta de multiprofissionalidade que, segundo Alvarenga et al. (2013), trata-se da justaposição de disciplinas distintas, em que os saberes especializados balizam a atuação de cada profissional. Assim, são convocados profissionais de diferentes áreas, como assistentes sociais, cientistas sociais, educadores físicos, oficineiros para atividades variadas, e redutores de danos em um segundo momento, possibilitando assim um espaço de construção de múltiplos saberes e revisão dos "postos" tradicionalmente estabelecidos (Silva, 2014a).

Essa entrada não foi simples para os novos profissionais, mas com obstáculos relacionados ao domínio das profissões já estabelecidas nos serviços, que utilizavam termos e nomenclatura específica para se referir a tratamento, medicação etc, e posicionavam-se de forma hierarquizada, destacando-se principalmente psiquiatras que além do saber advindo da medicina, são os únicos que prescrevem medicação, o que lhes fornecia um lugar político de poder (Silva, 2014a). No bojo dos desafios voltados às relações de poder, Silva destaca a questão do imaginário dos profissionais da equipe sobre tais relações. Além da característica específica da prescrição de medicamentos, nenhum profissional é, a priori, imprescindível na equipe. Assim, Silva aponta para a necessidade de pensar coletivamente sobre a formação da equipe, arguir sobre sua estrutura, com vias a pautar uma proposta que seja desinstitucionalizante.

O autor problematiza a formação profissional nos moldes da internação psiquiátrica, que é justificada na medida em que apresenta tecnologias de trabalho e a possibilidade de capacitar profissionais para fazer uso correto dessas tecnologias, mas não desconstrói a lógica por detrás, justificando-se através da ideia de que será causado um "mal menor" se aplicada por pessoas habilitadas, no caso os médicos (Silva, 2014a). A expectativa de vida de um paciente que viveu nos manicômios, fazendo uso contínuo de medicações e psicofármacos, muitas vezes sem prescrição acompanhada, era de aproximadamente 50 anos. As propostas voltadas ao trabalho e atividades nos contextos dos manicômios se inseriram na lógica capitalista da venda da força de trabalho como garantia de dignidade e possibilidade de compra e venda, proposta essa também implementada nos projetos de ressocialização em presídios, sendo, o manicômio, a própria "máquina de tratar" (Silva, 2014a). Nesse processo de desenvolvimento de tecnologias, aproximadamente entre os anos 1940 e 1950, é que surgem a 
convulsoterapia, eletroconvulsoterapia e as drogas antipsicotizantes. Silva destaca, contudo, que no final do século XIX, Freud desenvolveu a psicanálise como outra forma de cuidado, diferente do proposto pela medicina tradicional até então. Porém, a psicanálise é apropriada pelos médicos, que passam a aplicá-la.

Assim, o autor afirma que a proposta de constituição da equipe multiprofissional se relaciona com o advento da Declaração de Almaata (1978), em que propôs-se a extensão a atenção primária para toda a população, reconhecendo suas múltiplas necessidades e que estas poderiam não ser referentes a consultas médicas (Silva, 2014a). Essa perspectiva de expansão dos serviços de atenção básica apresenta a questão dos cuidados preventivos, proposta que deve ser analisada criticamente pelo olhar desinstitucionalizante, segundo Silva. O processo de fechamento dos hospitais psiquiátricos nos EUA (desospitalização), durante o governo Kennedy, não ofereceu nenhuma alternativa substitutiva; muitos dos pacientes ficaram sem respaldo de atenção adequada. A prevenção como recurso aparece no contexto da psiquiatria, com projetos que se voltavam a detecção precoce, como por exemplo do risco de jovens usarem drogas.

No Brasil, a formação de equipes multiprofissionais para atuar junto a saúde mental nos serviços de atenção básica são fruto da reforma sanitária. Contudo, esse processo iniciou-se em um momento onde milhares de leitos em hospitais psiquiátricos ainda funcionavam, dificultando assim o acesso de usuários a esse novo modelo de atenção, mas já propondo uma ampliação na oferta de cuidado. De acordo Yasui (2010), entende-se por cuidado a produção de uma ruptura com o modelo assistencial hegemônico, no qual é possível inventar dispositivos diferentes de trato, diversificar ações tecendo uma rede com o território, criar formas de sociabilidade, produzir novos valores sociais e construir uma ética na qual insiste-se em apostar num outro modelo possível.

Silva (2014b) aponta que realizavam-se consultas, psiquiátricas e psicológicas, no modelo do atendimento clínico do consultório, tal como era feito nos casos de neurose, que, para Roudinesco e Plon (1998), é um "termo é empregado para designar uma doença nervosa cujos sintomas simbolizam um conflito psíquico recalcado, de origem infantil", ao passo que ressalta-se aqui as particularidades das demandas que se diferenciam dos casos de psicose, como os que eram presentes nos serviços. (p.535)

Questionamentos sobre o direito da população poder ter acesso ao atendimento clínico eram colocados em pauta, porém o trabalho mostrava-se ineficiente $e$ insuficiente no caso dos pacientes psicóticos.

Então a ideia do Núcleo de Apoio Psicossocial e do Centro de Atenção Psicossocial, as duas modalidades que surgiram mais 
ou menos nessa época, são exatamente a ideia de fazer unidades que tenham algo do cuidado que o hospital faz no sentido da responsabilização pela pessoa e que tenha algo no ambulatório. Então digamos assim, para psicóticos, ambulatório é pouco e internação é demais. (Silva, 2014b, 12:48).

Assim, segundo o autor, para fazer frente a desisntitucionalização manicomial era necessário considerar uma série de fatores, como: moradia, trabalho, convivência e cuidado. Em relação à moradia, construíram os lares protegidos; ao trabalho, organizaram as cooperativas; à convivência, abriram centros de convivência; a coordenação do cuidado deveria oferecer cuidado contínuo, cuidado esse que requer um manejo clínico (Silva, 2014b). A clínica mental surge, então, desse novo desenho, que será uma "unidade gerenciadora do processo da desinstitucionalização" (Silva, 2014b, 15:41). Para tanto, é necessário desenvolver um certo tipo de manejo, que se volte ao cuidado, à interrelação, fornecendo ao sujeito apoio e suporte para sua movimentação nos diversos ambientes sociais:

E isso envolve uma noção de um fazer de tipo clínico, certo? Tudo que a gente tinha até então é o fazer da psiquiatria com a medicação, o fazer da psicologia com a psicoterapia, o fazer da terapia ocupacional com as oficinas dentro dos hospícios, o fazer do serviço social com a administração da relação com a instituição, com os familiares do sujeito que está internado. Esses são os velhos profissionais dos velhos fazeres. Agora eles vão vir para um novo espaço, onde eles devem reconstruir isso, e óbvio que o arranjo que a gente recebe é um arranjo que está instituído na saúde, desde o campo da atenção primária. (Silva, 2014b, 16:50)

A instauração de equipes multiprofissionais traz um questionamento à hegemonia médica, representando, de alguma forma, um processo de democratização no contexto do cuidado em saúde mental. Como destacado anteriormente, esse processo ocorreu com equívocos e desafios, todavia representava um ganho no desenvolvimento das relações de trabalho. Era preciso reconhecer, também, que apenas juntar profissionais de diferentes campos não garantia a qualidade do cuidado. A qualidade do cuidado não é inerente ao fato do profissional ter cursado o ensino superior e estar, naquele momento, reunido com outros profissionais no serviço de saúde. O autor aponta para a necessidade de capacitação, treinamento, diálogo, e uma série de fatores que os processos seletivos que recrutam profissionais para os serviços de saúde mental, através de concursos públicos, não contemplam: 
Depois que entra um monte de gente incapaz e as pessoas usam essa expressão "sem perfil". Cidadãos brasileiros, cidadãs brasileiras com seus legítimos direitos adquiridos constitucionalmente porque fizeram um concurso público. Mas nós precisamos, a reforma psiquiátrica, uma arguição sobre os rumos da reforma psiquiátrica, nós precisamos pensar seriamente na qualificação dos processos através dos quais se adquirem os recursos, as pessoas que vão fazer parte dessa responsabilidade de gestão. (Silva, 2014b, 24:30).

Silva não direciona nesse momento para o tipo de contratação que acredita que deveria ser feita, nem de que forma, mas aponta para a necessidade de pensar na administração do serviço e refletir sobre o processo de preparo e admissão de profissionais para serviços de saúde mental. O trabalho realizado, nos diferentes formatos que pode ser desenvolvido, requer criação de vínculos, relações, comprometimento, que fornecerão suporte para o cuidado do usuário e promoverão, de alguma forma, uma "facilitação da sua existência" (Silva, 2014b, 31:34). As demandas presentes no CAPS são variadas, contudo o autor aponta para a necessidade do cuidado específico nos casos de psicose, que de acordo com Freud (1996) é a referência à condição de repúdio e perda de realidade presente que o faz substituir a realidade posta, de modo que casos assim apresentam grande desorganização e ressonâncias sociais de maiores implicações, como também podem ser o caso de dependentes químicos, representando um desafio significativo aos profissionais e aos serviços:

O que é que tem o psicótico e o usuário problemático de droga em comum? Perturbam muito a ordem social. O que demanda a sociedade em relação a essas pessoas? Que eles não perturbem a ordem social. Como é que nós vamos conseguir fazer com que não perturbem a ordem social? Internando num manicômio, internando numa comunidade terapêutica, ou manejando essas experiências na convivência social, criando a possibilidade para que essas experiências estejam fazendo parte da convivência social? Esse é o ponto: a habilidade que se pede. $O$ que se quer dos profissionais, que não necessariamente tem a ver com uma equipe multiprofissional, com perfil " $x, y, z$ " mas tem a ver com uma equipe que tenha a perspectiva da interdisciplinaridade, não a perspectiva da multiprofissionalidade. (Silva, 2014b, 32:55)

A perspectiva da interdisciplinaridade volta-se mais ao compartilhar de saberes como forma de enriquecer o olhar e o manejo junto aos 
usuários, e não aprender e executar o que as demais disciplinas fazem, tampouco acreditar que a equipe multiprofissional em si representa a garantia de cuidado com qualidade.

A proposta de Silva nesse encontro é justamente questionar as "falsas soluções" dadas para o tratamento dos usuários, que em muitos momentos existiram através, por exemplo, da crença de que ter diversos profissionais de diversas áreas no serviço seria a garantia de cuidado efetivo. O autor destaca a importância da implementação de equipes multiprofissionais, principalmente no que se refere ao processo democratizante frente à áreas hegemônicas, ao agregar de diversos atores que antes não imaginavam que teriam espaço de trabalho junto a esse contexto, mas critica o viés corporativo que essa conjuntura assumiu. Assim, para Silva (2014b), é necessário manter o "pensamento vivo, o questionamento, o estranhamento", pois a realidade que se mostra é complexa, e muitos profissionais tem experiências negativas nesses espaços.

Nós precisamos de reengenharia dos processos de saúde mental. Algumas equipes, alguns serviços, tem conseguido fazer isso. A maior parte dos serviços é como se estivessem ambientados, como se fossem completamente sujeitados numa regra, numa norma, num conceito e ideias que estão inscritas em algum lugar e agora todo mundo tem que seguir assim. Quantos coordenadores de saúde mental tem ocupado lugares institucionalizantes, e tem tido perspectivas muito institucionalizantes para os personagens do processo? Através de uma proliferação de normatividade, de padronizações de conduta e todo tipo de coisa, que produzem uma asfixia e traz uma ilusão de mais organização, mas é só ilusão. Os processos de trabalho mesmo são os processos às vezes muito penosos para os trabalhadores. São muito penosos. Viver numa equipe dessas, as pessoas se cansam, é terrível, não tem prazer de trabalhar, então tem alguma coisa errada aí. (Silva, 2014b, 42:02)

Há, de acordo com o autor, a necessidade de questionar a organização dos processos de trabalho e, no caso de processos de trabalho coletivos, os diversos fatores que o constituem, como o lugar do conhecimento, as condições de refletir sobre esses processos, bem como construir uma relação com o usuário. Apontase, então, para a necessidade da construção de um trabalho em conjunto, dialógico e próximo, entre a equipe e junto aos usuários, onde as construções de relações serão condição fundamental para a efetividade do cuidado e para o desenvolvimento da proposta de diagnósticos diferenciais. 


\section{Diagnóstico diferencial: patologias ou formas de existência humana?}

Fomentando reflexões sobre o diagnóstico diferencial, Silva (2015a) propõe como recurso fundamental para clínica o fenômeno da transferência e a compreensão desse fazer clínico como relação. Pensar sobre a "clínica mental", "a clínica dos transtornos mentais" ou a clínica com "pessoas que se desorganizam psiquicamente e causam problemas com a dissonância comportamental" é uma discussão ampla que contempla inclusive posicionamentos distintos acerca da nomeação atribuída para a compreensão do fenômeno. No contexto da Reforma Psiquiátrica italiana, experiência desenvolvida por Franco Basaglia e importante referência para a Reforma Psiquiátrica brasileira, a concepção de loucura como doença mental é radicalmente criticada, tendo em vista o processo histórico que a originou (Rosa, 2016). Silva (2015a) salienta sua preferência pela denominação de "clínica da coisa mental" como referido no item 1, de modo que abrange assim as formas de compreender o fazer em relação a esses fenômenos.

O autor apresenta em seus Seminários uma percepção distinta sobre - diagnóstico diferencial, distante da perspectiva nosológica psiquiátrica que lida com síndromes e quadros de doenças, ancoradas num entendimento da patologia e que devem, portanto, ser curadas. É feita referência à clínica psicológica que por momentos se afasta e repudia essa compreensão nosológica, entretanto conserva na sua prática em muitos casos, uma dimensão ortopédica, no qual se faz presente a "ideia de desvio", de que algo deve ser corrigido.

A partir dessa perspectiva, Silva (2015a) discorre sobre o diferencial levantando questionamentos essenciais para aqueles que trabalham com a saúde mental, sobre quais elementos diferenciam certos tipos de sofrimento de outros, de modo que, por lidarem com distintos tipos de sofrimento e subjetividades, espera-se no imaginário social que esses profissionais tenham a clara compreensão do que os diferencia. Entretanto, pontua:

A clínica diferencial não é a clínica das diferenças de cada sujeito, de um para o outro, mas diferencial no sentido de que o sofrimento mental pode ser compreendido como derivado de certas formas de ser, e de que os sujeitos, portanto, tem mais do que "patologias", mas sim certas formas de existir. (Silva, 2015a, 06:24)

Avança na discussão sobre uma compreensão a partir da psicanálise, a respeito do conceito de "estruturas", embora destaque em sua fala a resistência no campo psi à esse termo. Silva (2015a), retoma Claude Lévi-Strauss com a noção de estruturalismo, como uma forma 
de compreensão do fenômeno social, antropológico, psíquico, sobre a forma de que são estruturas. A partir dessa linha de pensamento, deriva a compreensão referida anteriormente de que temos certas formas de existir, exemplificando a partir da ideia de neurose, psicose e perversão como estruturas, através do pensamento freudiano.

Para Silva (2015a), o entendimento de uma estrutura não tem sido, muitas vezes, uma noção clara no campo psi, tal como a ideia de diagnóstico. A ideia de diagnóstico diferencial, na psiquiatria, referese a como fazer a distinção de um quadro patológico de outro; no caso do campo psicanalítico, a noção de diferencial está relacionada à ideia de que os profissionais da saúde mental estão lidando, antes de tudo, com formas de existir, e de que assim os sujeitos estão enquadrados nessas formas, reforçando a intolerância do campo dos profissionais da psicologia sobre esse "determinismo, enquadramento", denominando esses conceitos como algo rígido, algo imutável, inconcebível para esses que atuam com a ideia de transformação dos sujeitos.

Ao longo de sua narrativa, o autor expressa seu desconforto frente ao campo psi estar subsidiado pela forma classificatória da psiquiatria, que dá o rumo da compreensão dos trabalhadores da saúde mental a partir dos DSMs e suas variações. Essas variações, muitas das vezes, comportam maior ideia de plasticidade quando comparadas à ideia de estrutura, que trabalha com algo muito elementar para enquadrar as formas de expressão humana, discussão essa que é essencial na perspectiva da desinstitucionalização. Silva (2015a), afirma que hipóteses estruturantes são fundamentais para trabalhar sobre o tipo de experiência que está se apresentando para os/as trabalhadores/ as da saúde mental.

Ainda sobre o entendimento acerca do diagnóstico, o autor afirma que por vezes acaba servindo tal como uma certificação no sentido de satisfação narcísica daquele que está diante do desafio que se apresenta, tal como na experiência psicótica. Retoma as denominações que muitas vezes são atribuídas aos sujeitos, no qual intitula-se quase como uma entidade ficcional "o psicótico", "o drogadito", "o toxicômano", onde as pessoas rotulam características, e servem nos serviços à ideia do diagnóstico que nesse caso atua como uma contraclínica, do que a qualquer ideia que se possa fazer como relação. Silva (2015a) afirma que essas entidades nomeadas ancoram as fantasias daqueles que os recebem no serviço, para as fantasias dos sujeitos que têm fantasias, de forma que esses termos dizem muito mais sobre os profissionais e uma forma de sedar essa ansiedade que desperta ignorância, que são inabilitantes para clínica. Considera ainda que um dos sintomas importantes da desorientação da Reforma Psiquiátrica está centrado nesse fazer diagnóstico. Assim, levanta o questionamento sobre a verdadeira função do diagnóstico: afinal, a quem serve o diagnóstico? Para que serve? Expressa a 
preocupação com a reforma numa perspectiva substitutiva e desinstitucionalizante, de modo que é importante frisar o horizonte desse movimento, que é produzir orientação para ação clínica, para as milhares de pessoas que trabalham para além da classificação "mesquinha" das escolas psicológicas? Entende-se que a crítica feita pelo autor não se refere estritamente a produção teórica dos diferentes campos da psicologia e a adoção da conceituação psiquiátrica, mas ao uso que se faz dessa produção e a sua função para o trabalho junto a clínica da coisa mental no encontro com o sujeito em sofrimento.

Outro ponto de destaque nesse Seminário Livre é a noção de que a psicose não é uma variação da neurose, e daí a importância da afirmação sobre as orientações psicanalíticas sobre estrutura. Silva (2015a) discorre sobre a essencialidade da discussão sobre esse tema, pautando a vivência da psicose não como uma derivação; ou seja, a psicose não é um evento de alguns fatores sociais que a pessoa está vivendo e desencadeiam crises. Exemplifica que uma expressão que reafirma a inclinação desse pensamento é "o surto psicótico", como se de repente a pessoa desistisse de ser neurótica e houvesse um afrouxamento da neurose. Silva (2015a) mostra a problemática dessa ideia de que o sujeito pode ter um surto e que depois, portanto, ele pode voltar a ser neurótico; o dito "conto de carochinhas psicológico acerca do sofrimento psíquico", discordando assim daqueles que dizem "todo mundo pode ter um surto um dia". Complementa afirmando:

Louco não é para quem quer, mas para quem pode, de modo que a experiência da ordem não está à disposição dos miseráveis neuróticos. (Silva, 2015a, 29:59)

Silva (2015a) faz alusão à Freud em relação ao sofrimento comum, discorrendo sobre o arranjo neurótico no sentido de ser um registro existencial e de que a miséria neurótica é um estado de sofrimento que é possível derivar do sofrimento comum, que pode conduzir assim à efeitos de saída desse estado anterior. O autor afirma que ser psiquicamente miserável é ser sem recursos, e é ser insuportável para os "outros", pois há ali muitas defesas psíquicas a maior parte do tempo. Assim, há a importância em organizar os trabalhadores da saúde mental frente aos sofrimentos que recepcionam, buscando a diferenciação diante da miséria neurótica e do tipo de atitude que devem ter diante da psicose. Pensando a partir daí, desenvolve-se o Seminário através do tema da compreensão da psicose e como aquilo que é distintivo, correndo riscos de que a relação que se tem com esses fenômenos ser, a priori, de absoluta ignorância: 
Não sabemos como é o funcionamento psíquico de um psicótico e não saberemos jamais, tudo que sabemos desse funcionamento psíquico se dá através do registro da neurose. Os encontros como aulas, eventos dentro da sociedade, são eventos organizados sobre o registro da neurose, em nome da neurose, tal como uma confraria da neurose. Só em companhia da psicose é que tudo que experimentamos faz parte da "sociedade anônima da neurose s/a", a própria ideia de sociedade, ser sócio, compartilhar palavras, o que nos faz em sociedade é um tipo de compartilhamento de palavras, numa modalidade de compartilhamento. (Silva, 2015a, 37:54)

Nesse sentido, há a distinção compreendida pelo autor sobre a neurose e psicose entre os sujeitos em seus processos de desenvolvimento e de que modo adquirem características de manejo simbólico para comunicação intersubjetiva, que achamos que é possível à comunicação humana. Silva (2015a), exemplifica “Vocês lidam com as suas ideias sobre o que eu falo e não com o que eu falo, afetados pela minha palavra. Existe uma rede de afetações pelas palavras, por isso há uma condução das palavras. Onde minha palavra leva vocês? Esse é o registro da neurose".

O autor fala ainda sobre a autoconsciência da neurose enquanto estrutura psíquica, como fator fundamental, mas para os sujeitos em sofrimento, desorganizados psiquicamente, há outras implicações. Refere-se à última como a expressão de um esforço de autopercepção de funcionamento psíquico, "é se dar conta de que você funciona psiquicamente". Silva (2015a) afirma que produzir reflexões sobre esses temas é tal como jogar lenha na "caldeira do funcionamento psíquico", pois precisamos reconhecer nosso funcionamento psíquico enquanto indivíduos, porque ser sujeito significa ter um funcionamento psíquico na nossa sociedade. Ao se referir ao "nosso" podemos considerar os profissionais da saúde mental e a necessidade do olhar para si nesse processo.

Ainda sobre a neurose, há destaque para a discussão sobre os mecanismos de defesa psíquica nesse registro, como a racionalização: transformar em raciocínios. Ou seja, os sujeitos se defendem subjetivamente produzindo pensamentos na neurose. A normalidade neurótica é aquela capaz de raciocinar, que pensamos ser o "suprassumo" da competência racionalizadora; tornar racional é dominar no registro simbólico, pois só se "domina" algo quando se transforma em algo "pensável"; exercer domínio sobre a realidade é o que fazemos corriqueiramente, no âmbito da neurose. Entretanto, não são todos que podem produzir o domínio da racionalização, apenas aqueles que sabem "falsificar": o registro da neurose seria o registro da "falsificação". Silva exemplifica a obsessão neurótica acerca da honestidade, tal como a fobia e a histeria, e afirma que até 
mesmo no "bloco da neurose" há um diagnóstico diferencial. Para ele é o campo em que terapeutas, cuidadores, mais se sentem "à vontade" pois há a possibilidade projetiva, e mesmo sem esquemas teóricos para guiar, aquele profissional se guia pela sua projeção e é onde a psicoterapia vai enfatizar tanto a questão da empatia, ou seja, a capacidade de se colocar no lugar do outro.

Silva (2015a) elabora reflexões sobre "o tratar pessoas" de modo que, para esse exercício, é preciso mudar a qualidade de percepção sobre o que sustenta a própria ontologia, auto sustentação ontológica, ao passo que o mote do sustentamento psíquico é manter o pilar do sujeito de que "você é você", que o autor toma como o conceito de ego e se trata daquilo que em nós, indivíduos, sustenta a existência, sustentação ontológica de estar no ato em frente ao outro. Assim, pensar que a questão ontológica se dá de maneiras distintas frente à neurose e à psicose, a pergunta "o que é o outro?", "o que é o eu?", fala acerca da universalização da ideia de sujeitos psíquicos, e aqui em destaque sobre a postura daqueles que trabalham no campo psi, que é antes de tudo se colocar também enquanto sujeito psíquico, mas especializado em cuidado de outros sujeitos psíquicos. Portanto, pensar assim é afirmar que não há mais "colegas de profissão", "pacientes", mas sim sujeitos psíquicos trabalhando psiquicamente de modo permanente.

Compreender que os modos de operar não são universais, mas corresponde daquilo que se estrutura simbolicamente, pois nós somos os da representação. O registro da neurose é simbólico, nós iludimos com a palavra, por isso talvez para neurose seja algo tão importante a sinceridade. Neurose como um recurso para lidar plasticamente com a realidade. Os mecanismos de defesa do ego, que existem na experiência da neurose, são fundamentalmente manipulações simbólicas. Neurose é constituída competência de manejo simbólico. A psicose só pode ser compreendida a partir dessa diferença com a qual o registro simbólico está a disposição para que sujeito o manuseio, utilize. A psicose corresponderia a uma determinada relação com a palavra onde o sujeito nunca se sente sócio, onde a ilusão da intersubjetividade não está fácil nem tampouco disponível, não é para todos. E é o que constitui a natureza do social, a sociedade é constituída da neurose, ninguém ouviu falar sobre sociedade dos psicóticos. Só para quem é sócio da palavra que comporta a ilusão da intersubjetividades; os que estão fora disso estão no registro da psicose. (Silva, 2015b, 00:27)

A comunicação tem a ver com 'pôr em comum, compartilhar do comum' o que constitui o sujeito social. É o formato de sujeito 
psíquico que só é adquirido na condição de pertencimento à sociedade e é ter inscrita as possibilidades de significação; o que nos torna comum na neurose é a possibilidade de inscrição do simbólico. Silva (2015b) fala também sobre a solidão psicótica, pensando no não compartilhamento da palavra e das significações, de modo que a palavra é o instrumento para se produzir sócios nas instituições sociais que são reiterações do mesmo, daqueles que compartilham o comum. Essas sociedades vão se identificando, sociedade receptáculo com valores liberais, individuais na reprodução da experiência. Somos sócios através da relação eu e outro, ser neurótico é dar resposta a "eu e ao outro", é compartilhar o registro, enquanto ser psicótico é dar outra resposta de enquadrar esse tema. Ou seja, diagnóstico diferencial fundamentalmente tem a ver com a dimensão da inscrição simbólica que subjetivamente a experiência do "eu e do outro" deve ser equacionada e pensada estruturalmente.

Silva (2015b) fala sobre a oferta do "melhor de si performático", como a melhor competência psíquica que apresentam para nós, exemplificando a partir do delírio que também é a melhor versão possível do sujeito. Reitera que os sujeitos estão sempre no melhor de si, o melhor que se pode e que se apresenta; é aquilo que efetivamente é expresso pelo sujeito psíquico. Assim, o suportar da ignorância sobre o outro se faz como algo fundamental, pensando sobre os episódios de objetivação dos sujeitos, em contraponto ao alerta do não lugar da hipótese, do não benefício da dúvida nos serviços de alta complexidade que demandam encaminhamentos para o manejo com a coisa mental.

Por fim, há também um alerta para "democracia psíquica", outro conto de carochinhas psicológico, que acontece como se todos fossem iguais psiquicamente perante a lei. Logo, qualquer um poderia ficar no lugar de psicoterapeuta, pois vai lidar com sujeitos iguais a ele, na máxima "todo mundo é igual", como se as realidades psíquicas fossem todas passíveis de serem inscritas em registros identificatórios. Silva (2015b) denomina esse fenômeno como desorientação no campo do fazer clínico na perspectiva da Reforma Psiquiátrica, antimanicomial e substitutiva, "estado mental coletivo da comunidade", um modo de funcionamento dessa enigmática e complexa tarefa de lidar com pessoas em sofrimento mental.

Silva (2015b) faz ainda um adendo sobre a experiência do uso de substâncias, como a cannabis sativa, que para alguns acontece com pouca capacidade desrealizadora e outros com muita potência. Legitima a "necessidade psíquica" dos indivíduos frequentarem lugares com realidades alternativas à essas que temos no mundo compartilhado por alguns, como uma forma de desrealização psíquica produzindo deslizamentos psíquicos à certos arranjos mentais, que podem se aproximar de experiências próximas da vivência da psicose. Há um debate médico importante sobre a relação entre 
maconha e psicose, considerando que o efeito da cannabis pudesse ser desencadeante da psicose; o problema disso para o autor é que não há compreensão sobre todos os que fumam maconha regularmente e não desencadeiam psicose, no qual há a experiência de desrealização, mas não psicose. Daí os questionamentos da sociedade compartilhada: "o efeito de desencadeamento de psicoses quando sujeitos fumam maconha não estaria associado à pré condição do sujeito mais do que à ingestão da droga?". Silva (2015b) reflete sobre a questão atentando que os fatores de desencadeamento, afloramento, poderiam ser um susto, um casamento, interpelação do chefe (...) várias situações e até a ingestão da droga, entretanto destaca em sua reflexão a presença ou ausência de recursos que os sujeitos tem para lidar com essas condições. Sujeitos têm arranjos psíquicos com alguns recursos e outros sujeitos com outros, então considera-se 0 diagnóstico diferencial para compreensão dessas estruturas e recursos.

O autor retoma o paralelo de que a crise psicótica é a expressão da falta de recursos do sujeito para lidar com algumas demandas, sendo concernente ao campo simbólico. Enquanto as pessoas acreditam que o surto seja a expressão do "caos destruindo tudo", não é, pois o pior já aconteceu; de acordo com ele, "o surto é o fundo do poço da desorganização psíquica". O pior na psicose é a impossibilidade de lidar com as questões no registro simbólico, sendo o surto a resposta. E o trabalho seguinte é o trabalho da reconstituição do laço simbólico. Silva (2015b) dá ênfase ao longo de seus Seminários para um tratamento em que o sujeito saia, objetivamente e subjetivamente, do insuportável para o mais suportável, pois todos os sintomas e efeitos são resultados do insuportável para aquele sujeito. Para ele, os sintomas psiquiátricos são expressão do insuportável para o sujeito, sem decodificação desses sintomas, recursos pessoais e intransferíveis que o sujeito organiza para dar conta da realidade que está difícil. Para aqueles que trabalham no cuidado com a coisa mental, é necessário lembrar que são cuidadores de modos psíquicos, sendo sujeitos psíquicos também, tentando existir e dar conta dessa existência, de modo que a teoria é o recurso que os diferencia e seria, nesse caso, o diagnóstico diferencial daqueles que realizam esse cuidado.

\section{Considerações finais}

A partir das contribuições das discussões realizadas nesses dois encontros dos Seminários Livres Qlinica, com quê?, é possível destacar o percurso proposto por Silva (2014b, 2015b) ao apontar para a modificação dos serviços no bojo da Reforma Psiquiátrica, nas perspectivas da desinstitucionalização e substitutividade. A primeira, 
volta-se à desinstitucionalização das formas de 'cuidado' do modelo manicomial, bem como à necessidade do constante questionamento sobre as formas institucionalizadas no fazer da atenção básica, e a segunda volta-se a necessidade da constituição de um modelo substitutivo ao referido, desmembrando ferramentas e estratégias de cuidado para se aproximar do horizonte almejado, o exercício da Reforma Psiquiátrica. Nesse contexto, o autor apontou para os diversos desafios presentes no sustentamento dessas perspectivas, destacando a formação de equipes multiprofissionais que representaram um avanço no processo de integralidade na proposta de cuidado, democratização frente aos demais saberes instituídos, contudo não representam em si uma garantia de cuidado qualificado e atenção efetiva. Para Silva (2014b), é necessário desenvolver um trabalho interdisciplinar, do ponto de vista do compartilhar de saberes e diálogo junto à equipe, que será uma das bases para que o processo de trabalho coletivo se desenvolva. Contudo, é preciso enfatizar que o trabalho junto à saúde mental requer a construção de vínculos e relações, para que seja possível desenvolver o manejo junto aos casos de psicose e ao desenvolvimento do diagnóstico diferencial, considerando a necessidade da autocrítica da condição estrutural psíquica da própria equipe para lidar com outros sujeitos.

Considera-se que as referências centrais do artigo, os seminários gravados em vídeo, apresentam possibilidades e limitações em relação à discussão proposta. Possibilidades, pois configuram-se como espaço de diálogo para estudantes e profissionais da rede, havendo abertura para questionamentos, articulações com temas variados feitos no contexto da discussão, mas limita-se no sentido de não apresentar um aprofundamento articulado tal como pode ser feito em um texto. Assim, entende-se esse recurso como uma possibilidade de difusão do conhecimento produzido por Marcus Vinícius, que pode ser enriquecido na articulação e debate com outras fontes de informação e campos teóricos. O autor faz referência a diversas áreas do saber, como a Psicanálise, e propôs-se aqui apresentá-las, compreendendo que a leitura feita por Silva envolve articulações variadas, por vezes com uma compreensão própria ou expandida da definição tradicional.

As contribuições do projeto Qlínica, com que?, expostas nesse estudo de maneira introdutória, abrange fundamentais temas voltados à construção e desenvolvimento da clínica ampliada no âmbito da Rede pública no manejo com a coisa mental. Além de versar sobre os aspectos que constituem o trabalho em rede, as discussões propostas por Silva (2014b, 2015b) apresentam-se como provocações fundamentais sobre os desafios do trabalho em equipe, considerando as relações de poder instituídas, a promoção de diálogo e as limitações no lidar com o sofrimento psíquico. Desenvolver um espaço formativo para o compartilhar desses desafios aponta para a 
possibilidade da criação de dispositivos clínicos e formativos junto à estudantes e profissionais, caminho esse que se apresenta como alternativa ao trabalho clínico junto à saúde pública. Destaca-se também a importância dessa discussão ser complementada considerando temas como a territorialização das intervenções em saúde mental, os vínculos pessoais, profissionais e comunitários e os desafios da construção de estratégias na atenção básica (BRASIL, Ministério da Saúde, 2013), além da necessidade de compreender a questão da loucura como não circunscrita ao campo da saúde, podendo assim superar a noção de doença mental e criar condições para a construção de projetos de vida (Rosa, 2016).

Cabe aqui destacar a fundamental importância de trazer à comunidade acadêmica as discussões propostas por Silva (2014a, 2014b, 2015a, 2015b), no que tange às expressões diretas acerca dos desmontes das políticas públicas e sociais que os equipamentos de saúde vem sofrendo na atual conjuntura. Trazer esse estudo dos Seminários realizados para os dias de hoje se mostra, portanto, fundamental como recurso para fortalecimento desses profissionais inseridos na rede para ampliar as estratégias de resistência no cuidado e manutenção da luta por uma sociedade sem formas manicomiais de compreender as expressões de existência que chegam até os serviços.

\section{Referências}

Alvarenga, J. D. P. O., Meira, A. B., de Fontes, W. D., Xavier, M. M. F. B., Trajano, F. M. P., Neto, G. C., ... \& de Almeida, F. V. H. (2013). Multiprofissionalidade e interdisciplinaridade na formação em saúde: vivências de graduandos no estágio regional interprofissional. Revista de enfermagem UFPE online-, 7(10), 5944-5951. doi: 10.5205/1981-8963v7i10a12221p5944-5951-2013

Brasil, Ministério da Saúde. (2013). Cadernos de Atenção Básica: saúde mental (Vol. 34). Brasília, DF: Ministério da Saúde.

Campos, G. W. D. S., \& Amaral, M. A. D. (2007). A clínica ampliada e compartilhada, a gestão democrática e redes de atenção como referenciais teórico-operacionais para a reforma do hospital. Ciência \& Saúde Coletiva, 12(4), 849-859. doi:10.1590/S141381232007000400007

Declaração, de Alma-Ata. (1978). In: Ministério da Saúde (BR). Secretaria de Políticas de Saúde. Projeto Promoção da Saúde (2001), Declaração de Alma-Ata; Carta de Ottawa; Declaração de Adelaide; Declaração de Sundsvall; Declaração de Santafé de Bogotá; Declaração de Jacarta; Rede de Megapaíses; 
Declaração do México (pp. 15). Brasília (DF): Ministério da Saúde.

Freud, S. (1996). A perda da realidade na neurose e na psicose. In S. Freud, Edição Standard Brasileira das Obras Completas de Sigmund Freud (Vol 19, pp. 205-239). Rio de Janeiro: Imago. (Trabalho originalmente publicado em 1924)

Nunes, M. R. M. (2004). Psicanálise e educação: pensando a relação professor-aluno a partir do conceito de transferência. Colóquio do LEPSI IP/FE-USP, 5. Retirado de http: //www. proceedings.scielo.br/scielo. php?pid=MSC0000000 032004000100040\&script $=$ sci_arttext\#tx

Rosa, E. Z. (2016). Por uma Reforma Psiquiátrica Antimanicomial: O papel estratégico da Atenção Básica para um projeto de transformação social (Tese Doutorado em Psicologia Social). Pontifícia Universidade Católica de São Paulo, São Paulo.

Roudinesco, E., \& Plon, M. (1998). Dicionário de psicanálise. Rio de Janeiro: Zahar.

Silva, M. V. O. [Instituto Silvia Lane]. (2014a, Novembro 4). A clínica ampliada da coisa mental, desinstitucionalização e subjetividade. Parte I [Arquivo de vídeo]. Retirado de https://youtu. be/IFW1f4glsNQ

Silva, M. V. O. [Instituto Silvia Lane]. (2014b, Novembro 4). A clínica ampliada da coisa mental, desinstitucionalização e subjetividade. Parte II [Arquivo de vídeo]. Retirado de https://youtu. be/qN1KqiMgSKc

Silva, M. V. O. [Instituto Silvia Lane]. (2015a, Março 17). Diagnóstico diferencial: patologias ou formas de existência humana? Parte I [Arquivo de vídeo]. Retirado de https://youtu.be/kJ mMt_-w3Us

Silva, M. V. O. [Instituto Silvia Lane]. (2015b, Março 17). Diagnóstico diferencial: patologias ou formas de existência humana? Parte II [Arquivo de vídeo]. Retirado de https://youtu.be/8KBCccf938

Yasui, S. (2010). Rupturas e encontros: desafios da reforma psiquiátrica brasileira (Tese de Doutorado). Escola Nacional de Saúde Pública, Fundação Oswaldo Cruz, Rio de Janeiro, RJ .

\section{Endereço para correspondência}

Bruna Borba de Araújo Tchalekian

Universidade de São Paulo - USP

Instituto de Psicologia

Programa de Pós-graduação em Psicologia Escolar e do Desenvolvimento Humano Av. Professor Mello Moraes, 1721, Butantã, CEP 05508-030, São Paulo - SP, Brasil

Endereço eletrônico: bruborba@gmail.com

\section{Yasmin de Sousa Pereira}

Universidade Federal do ABC - UFABC

Programa de Pós Graduação em Ciências Humanas e Sociais 
Av. dos Estados, 5001, Santa Terezinha, CEP 09210-580, Santo André - SP, Brasil Endereço eletrônico: yas.sousap@gmail.com

Recebido em: 18/12/2018

Reformulado em: 18/01/2019

Aceito em: 21/01/2019

\section{Notas}

* Doutoranda em Psicologia Escolar e do Desenvolvimento Humano pela Universidade de São Paulo. Docente no Curso de Psicologia das Faculdades Integradas de Ciências Humanas, Saúde e Educação de Guarulhos, mestre em Educação: Psicologia da Educação pela Pontifícia Universidade Católica de São Paulo.

** Mestranda em Ciências Humanas e Sociais pela Universidade Federal do ABC e psicóloga pela Pontifícia Universidade Católica de São Paulo.

Este artigo de revista Estudos e Pesquisas em Psicologia é licenciado sob uma Licença Creative Commons Atribuição-Não Comercial 3.0 Não Adaptada. 